\title{
1
}

\section{Children and Youth Have an Identified Health Care Home (Medical Home)}

Barbara Velsor-Friedrich and Patricia Vernal Burkhart

\section{Chapter Objectives}

1. Compare and contrast the potential significant health outcomes for children with chronic or developmental conditions who have a designated health care (medical) home and for children who do not.

2. Analyze the impact of the Patient Protection and Affordable Care Act (PPACA) on the potential for every child to participate in a designated medical home.

3. Describe the potential role of the nurse in coordinating the health and wellness of children who participate in health care homes.

4. Understand the principles of coordinated and integrated care in transitioning a child from a pediatric to an adult health care home.

5. Analyze gaps in the literature and the strength of evaluation metrics, such as the medical home index (MHI), to design studies that would contribute to the scientific rigor and interpretation of the outcomes data related to patient outcomes and associated costs (i.e., return on investment) for patients participating in a health care home.

\section{INTRODUCTION TO THE GUIDELINE}

The guideline discussed in this chapter is that all children and youth should have an identified health care home (medical home). Definitions of the term, history of the concept, and current research related to models of health care homes and their effect on pediatric health outcomes 
are discussed. The chapter concludes with recommendations for clinical practice, education, policy, and future research regarding health care homes for children and youth.

\section{Definitions of a Health Care Home}

A review of literature revealed several terms that were used synonymously with medical bome. Those include primary care models of health, patient-centered medical home (PCMH) model, coordinated care model, patient-centered Medicaid home, advanced Medicare home models, and health care home (Adams \&Tapia, 2013; American Academy of Pediatrics [AAP], 1992, 2002, 2013; American Colleges of Physicians, American Academy of Family Physicians, American Osteopathic Association, \& AAP, 2007; Antonelli, Stille, \& Antonelli, 2008; Cowell \& Swartwout, 2006; Grant \& Greene, 2012; Toomey, Chan, Ratner, \& Schuster, 2011). According to the AAP, a medical home is defined as an approach to providing comprehensive, high-quality primary care. Characteristics of the medical home include accessibility, continuity, comprehensiveness, compassion, cultural effectiveness, and family centeredness. In addition, a medical home is intended to build partnerships with clinical specialists, families, and community resources (AAP, 2016).

In a recent, position paper, the National Association of Pediatric Nurse Practitioners (NAPNAP) published the following definition of a health care home: "The delivery of children's health care should be family-centered, accessible, comprehensive, coordinated, culturally appropriate, compassionate, and focused on the overall well-being of children and families" (NAPNAP, 2016, p. 1).

\section{Historical Overview}

The concept that children and youth have an identified health care home (medical home) has evolved since the late 1960s and has evolved over time. The term medical home was first introduced in 1967 by the AAP to describe a central location for a child's medical records. The initial focus was on children and youth with special health care needs (CYSHCN; AAP Council on Pediatric Practice, 1967). Thirty-two years later, the Maternal and Child Health Bureau (MCHB) awarded a 5-year agreement to the AAP to establish a medical home program for children with special needs. The National Survey of Children with Special Health Care Needs and the National Center for Medical Home Implementation were developed as an outcome of this model. The National Center for Medical Home Implementation was recently awarded a 5 -year agreement from the MCHB to focus on the implementation of medical homes for children and youth in vulnerable and underserved populations (AAP, 2016). Over the years, the AAP has updated its definition of medical home, now called the patient-centered home, as well as developed policies related to the concept (AAP 1992, 2002, 2013, 2016).

The joint principles of the PCMH were published by the American Academy of Family Physicians, the AAP, the American College of Physicians, and the American Osteopathic Association in 2007. In 2010, the American Public Health Association recognized the health care home model as an important way to increase access to care, reduce health disparities, and better integrate health care within the public health systems (Grant \& Greene, 2012). As previously stated, the NAPNAP recently published a position statement on Pediatric Health Care/ Medical Home: Key Issues on Care Coordination, Transitions, and Leadership (2016). This position statement affirms that the "delivery of children's health care should be family-centered, accessible, comprehensive, coordinated, culturally appropriate, compassionate, and focused on 
the overall well-being of children and families" (p. 1). A recent survey found that $54 \%$ of all U.S. children and youth receive care within a health care home/medical home, whereas $43 \%$ of CYSHCN receive care within a medical home (National Center for Medical Home Implementation, 2016).

For purposes of this chapter, the term bealth care bome is used to denote inclusivity of nurses and other health care providers. This term was unanimously agreed on by the Child, Adolescent and Family Expert Panel from the American Academy of Nursing to indicate the variety of disciplines and the broad care that is required for the comprehensive, continuous care of children and families (Cowell \& Swartwout, 2006).

\section{GUIDELINE IMPORTANCE}

The health care home model has been recognized as an important way to increase access to care, reduce health disparities, and better integrate health care within the public health systems. The literature reveals that children who have a health care home have better overall health outcomes than those who do not (Cooley, McAllister, Sherrieb, \& Kauhlthau, 2009). This seems to be particularly true for CYSHCN (Homer et al., 2008). The majority of studies reviewed the use of health care home/medical home document outcomes of increased quality and reduced costs (Antonelli et al., 2008). The health care home model supports the goals of the PPACA to increase the quality, accessibility, and affordability of health insurance and health care to all.

\section{THEORETICAL/LITERATURE SUPPORT FOR THE GUIDELINE AND INDICATORS}

A computer search was conducted in the PubMed and CINAHL databases for original articles published from January 2005 through January 2016. The subject of the search was patientcentered care and included the key words medical homes, bealth care homes, outcomes, models, and children. The search resulted in 185 articles; duplicate articles were removed, yielding 142 articles; of those, 55 were identified for development of this chapter. The majority of articles included in the review were empirical studies, with some theoretical papers used for background and historical information on the topic. Excluded from the review were papers regarding health care homes for the adult population, since the focus of this chapter is children. The summary of the findings is discussed in the following categories: (a) outcomes for CYSHCN; (b) models of pediatric health care homes for CYSHCN; (c) outcomes for children with chronic conditions; (d) outcomes related to early childhood development and primary prevention; (e) outcomes related to CYSHCN with autism; (f) outcomes related to CYSHCN in foster care; and (g) transition of youth with special health care needs (YSHCN) into adult care.

\section{Outcomes FOR CYSHCN}

The MCHB defines CYSHCN as "those who have one or more chronic physical, developmental, behavioral or emotional conditions and who require health-related services of a type beyond that required by children generally" (MCHB, 2008, p. 8). Children with special health care needs (CSHCN) include approximately $20 \%$ of children and youth in the United States and account for $80 \%$ of pediatric health care expenditures (Centers for Disease Control and 
Prevention [CDC], 2016). CYSHCN have three times as many hospital bed days and school absences as do other children (Newacheck, Strickland, \& Shonkoff, 1998).

CYSHCN are less likely than other children to have private insurance and more likely to be enrolled in Medicaid or the State Children's Health Insurance Program (SCHIP). However, because of their high level of health care needs, CYSHCN often experience health insurance as inadequate (Oswald, Bodurtha, Willis, \& Moore, 2016). Fragmentation of care to this population results in high costs. The idea of a health care home/medical home has been supported as an effective way for implementing comprehensive and coordinated care for CYSHCN. Typically, CYSHCN require a large and varied health care team to provide and manage their care. Coordination of care for this population through a medical home was recommended more than 24 years ago by the AAP (1992).

\section{Models of Pediatric Health Care Home/Medical Models FOR CYSHCN}

A number of pediatric health care homes/medical home models for CYSHCN were discussed in the literature. In each of these modes of care delivery, a nurse or pediatric nurse practitioner (PNP) played a vital role, often as a case coordinator.

Interventions to operationalize the medical home for CYSHCN were conducted in six pediatric practices of the Pediatric Alliance for Coordinated Care (PACC). A PNP served as a case manager developing an individualized health plan for each child with special health care needs. Continuing education was provided to all health care professionals in each of the practices. The PACC medical home intervention increased parent satisfaction with care delivered to their child. In addition, the PACC model assisted practices to meet goals of functioning as a medical home with lower financial costs (Palfrey et al., 2004).

A tertiary care-primary care partnership model was evaluated for its impact on the health care of medically complex and fragile CYSHCN. The goal was to provide seamless inpatient and outpatient care and assist in providing medical homes. A special needs pediatric nurse provided care coordination for 227 children and their families. The tertiary care-primary care partnership model improved health care and reduced costs with relatively modest institutional support (Gordon et al., 2007).

A series of medical home improvements was implemented in 10 pediatric primary care practices teams. The improvements targeted enhanced clinical, functional, satisfaction, office efficiency, and cost outcomes for CYSHCN. The MHI was used to measure changes. This instrument was developed to enable practices to establish their own baseline data and document improvement (Cooley, McAllister, Sherrieb, \& Clark, 2003). The MHI consists of 25 items arranged in six areas of primary care office activity. It was found to be internally consistent with acceptable reliability and validity for pediatric primary care practices to assess the implementation of the medical home concept (Cooley et al., 2003). Over a 3-year period, the 10 practices demonstrated a $30 \%$ increase from their baseline MHI scores, resulting in significant clinical, functional, and use outcomes for 82 families of CYSHCN (McAllister, Sherrieb, \& Cooley, 2009).

The care coordination activities for CYSHCN in primary care settings were examined using a descriptive, multisite study of activities, personnel costs, and outcomes. A care coordination measurement instrument was used to record nonreimbursable care coordination activity encounters performed by office-based personnel. Office-based nurses providing care coordination were responsible for a significant number of episodes of avoidance of higher cost use outcomes (Antonelli et al., 2008). 
The effectiveness of a practice-based model of care (medical model) versus an agencybased model of care for CYSHCN was compared. The practice-based model used a nurse care coordinator. Training on quality improvement and the principles of the medical home was offered to the staff. Families that received care in the practice-based care model were more likely to report improvements in their experiences with the care, higher overall satisfaction with care coordination, and better treatment by office staff (D. Wood et al., 2009).

A study on the impact of a care coordination intervention aimed at improving the medical home for CYSHCN was conducted by Farmer, Clark, Drewel, Swenson, and Ge (2011). The sample of $100 \mathrm{CYSHCN}$ was randomly assigned to a care coordination intervention or a standard care group. Members of the care team included the child, family, primary care physician, and a designated nurse. A paid parent consultant was also available to offer information and support to families. Participants in the intervention group reported a decreased need for information and improved satisfaction with specialty care coordination and improved child health and family functioning.

Parent-reported outcomes of comprehensive care for children with medical complexity (CMC) were explored at Arkansas Children's Hospital Medical Home Clinic. CMC are identified as the highest resource users among all children because of their service needs, medical equipment use, and functional difficulties (Neff, Sharp, Muldoon, Graham, \& Myers, 2004). The medical home clinic provided multidisciplinary care oversight and tertiary care centerbased care coordination. A nurse coordinator was assigned to each patient and family. The study concluded that comprehensive care oversight may improve care coordination for parents of CMC; however, there was no association with improved patient health (Kuo et al., 2013).

After enrollment in a medical home, 120 of 174 parent respondents of special needs children reported improvements, from baseline to 12 months, in having a care plan, and fewer respondents reported needing help with care coordination (Kuo et al., 2013). The impact of having a medical home on outpatient medical costs for CYSHCN was examined in 1,140 children. Outpatient costs were significantly higher for all females and Medicaid-enrolled CYSHCN. In addition, costs were significantly higher for CYSHCN who were in a lower state of health, older children, and those enrolled in a health maintenance organization [HMO] (Damiano, Momany, Tyler, Penziner, \& Lobas, 2016). The authors concluded that medical homes may reduce inpatient costs more than outpatient cost for CYSHCN.

The relationship among child characteristics, household factors, and parental coping in parents with a CYSHCN with and without a health care home was examined. Secondary data analyses revealed that parents of CYSHCN who had a health care home that included care coordination, were more satisfied with provider communication and coped better than those who were not in a health care home (Drumond, Looman, \& Phillips, 2012).

The effect of a medical home on racial/ethnic disparities was examined for transition services for CYSHCN. A secondary analysis of national survey data revealed that transition rates and associated characteristics still differed by race/ethnic group. Recommendations included the development of culturally tailored interventions incorporating universal factors to improve medical home transition outcomes (Richmond, Tran, \& Berry, 2012).

A recent review of the literature regarding the evaluation of the use of a medical home for CYSHCN documented that a positive relationship existed between the medical home and desired outcomes. This included better health status, timeliness of care, family centeredness, and improved family functioning (Homer et al., 2008).

In summary, a key factor in the success of health care home models for CYSHCN was a pediatric nurse or PNP. The pediatric nurse or PNP often served as a case manager or coordinator, developing individualized health plans for each child/youth with special health care needs. Parents of CYSHCN who participated in these studies reported greater satisfaction with the 
care delivered to their child as well as increased satisfaction with provider communications. Hospital-based practices and pediatric practices that participated in the health care home model reported an improvement in patient health outcomes, an increase in office effectiveness, and a decrease in financial costs. Two instruments, the MHI and the care coordination measurement instrument, were used to assess changes in outcomes for CYSHCN. There is a still a need to develop interventions that are culturally designed for race/ethnic group.

\section{Outcomes for Children With Chronic Conditions}

Children whose families lack medical insurance often use the emergency department for their primary care needs. This can result in fragmented, disrupted care. The primary care health care home has been endorsed by the AAP for its emphasis on planning, coordination, continuity, and family-centered care (Adams \& Tapia, 2013; Cooley et al., 2009). There is mounting evidence that health outcomes improve with the implementation of health care homes for all children but in particular for children with chronic conditions. Fewer hospitalizations and emergency department visits occurred in children with chronic conditions $(N=880)$ such as asthma, diabetes, cerebral palsy, epilepsy, autism, and attention deficit hyperactivity disorder (ADHD), who received care from a PCMH (Cooley et al., 2009). In a retrospective, crosssectional study of 240 low-income children with chronic conditions who received treatment as part of a health plan primary care practice, lower rates of hospitalization and emergency department visits were found (Raphael et al., 2015). Measures of analyses were parent surveys and primary care practice self-assessments (i.e., MHI) that suggested having a primary source of care and an organized approach resulted in lower acute care use (Raphael et al., 2015).

When specific chronic conditions, such as asthma, were considered, the outcomes indicated that children enrolled in a health care home demonstrated decreased use of hospital and emergency department services (Domino, Humble, Lawrence, \& Wegner, 2009). There were also significant reductions in asthma severity attributed to the best practices of asthma management in a pediatric health care home that resulted in cost savings as a result of improved health outcomes (Grant, Bowen, Neidell, Prinz, \& Redlener, 2010). In addition, evidence suggests that children with asthma who have a usual care provider are more likely to have regular wellness examinations (Kieckhefer, Greek, Joesch, Kim, \& Baydar, 2005).

Six clinics delivering care to youth with HIV were surveyed to assess their compliance to PCMH care. Overall, clinics scored highest on coordinated care, as well as quality and safety measures, and lowest on health information technology (IT), accessible services, and comprehensive care (Yehia et al., 2013).

Of the 52,000 children aged 6 to 17 with ADHD whose parents responded to the 2007 National Survey of Children with Special Health Care Needs $(N=92,000), 44 \%$ of the children received care from a medical health care home. PCMH criteria included parent reports of all of the following: (a) personal doctor or nurse; (b) family-centered care (when applicable); (c) problem-free referrals (when applicable); (d) a usual source of care; and (e) coordinated care (when applicable). These children had significantly better health outcomes compared with children with ADHD not participating in a health care home (Toomey et al., 2011). Children with ADHD who received care in a PCMH were more likely to receive ADHD medication, less likely to require involvement of a mental health specialist, and less likely to have behavioral problems and had fewer missed school days (Toomey et al., 2011).

In summary, studies provided evidence that children with chronic conditions who are enrolled in a health home have better coordination of care, resulting in improved health outcomes. For many of these children, better health outcomes can include significant reductions 
in acute care visits, such as hospitalizations and emergency department visits, impacting health care costs.

\section{Outcomes Related to Early Childhood Development and Primary Prevention}

Improved long-term outcomes for early childhood development have been found for children enrolled in health care homes that focused on effective screening, coordinated care, and referrals (Adams \& Tapia, 2013). A study investigating a possible modifying effect of a medical home on the association between low birth weight and children's health outcomes did not find a significant effect. The medical home was not found to be an effective modifier between low birth weight and poor outcomes (i.e., the presence and severity of physical, developmental, and psychological conditions) for children up to 5 years of age (Salas, Xaverius, \& Chang, 2012). A limitation of this study was that it was a cross-sectional, secondary analysis of the 2007 National Survey of Children with Special Health Care Needs that did not assess the relationship over time (Salas et al., 2012).

An assessment of pediatric medical homes and relationship to beneficial child outcomes documented that comprehensive care was associated with improved child health and health care use and decreased outpatient and emergency department sick visits (Long, Cabral, \& Garg, 2013). In addition, a significant positive effect was found in states with higher rates of children participating in a health care home and children receiving childhood vaccines (Seipel, 2011).

A particularly vulnerable population are patients with limited health literacy for whom health care utilization can be very costly. When health education is provided in an easily understood format and action plans are individualized and implemented within a health care home model, health care utilizations with resultant costs can be significantly reduced (M. R. Wood \& Bolyard, 2011).

A cross-sectional analysis of the 2007 National Survey of Children with Special Health Care Needs with 92,000 parent respondents of children birth to 17 years of age did find that $57 \%$ of the children received care provided by a medical home (Strickland, Jones, Ghandour, Kodan, \& Newacheck, 2011). Children not enrolled in a health care home were more likely to have unmet health care needs that included dental care (Strickland et al., 2011).

An early childhood dental caries screening tool for children within a medical home model resulted in higher rates of referrals preintervention and postintervention during children's 9-, 12-, and 18-month well-child visits (Jackson, 2015). However, this study did not include a control group of children not enrolled in a medical home.

Standardized nutrition therapy delivered to overweight children in their medical home resulted in significant decline in weight status, determined by body mass index (BMI; Henes, Collier, Morrissey, Cummings, \& Kolasa, 2010; Quattrin et al., 2014). Although these studies were not randomized clinical trials of children enrolled in health homes compared with children who were not, the results suggested that tested treatment protocols delivered in a collaborative, coordinated care model with consistent follow-up show promise for effective weight control in youth.

In summary, studies related to early childhood development and primary prevention suggested that coordinated care for children enrolled in health homes demonstrated improved health outcomes. Children not enrolled in a health care home were more likely to have unmet primary prevention needs, such as lack of vaccinations, dental care, and nutrition education, and follow-up to maintain appropriate weight gain in childhood. 


\section{Outcomes Related to CYSHCN With Autism}

A systematic review of the literature concluded that children with autism spectrum disorder (ASD) need greater access to coordinated care available through a medical home (Tregnago \& Cheak-Zamora, 2012). Families of children with ASD have higher health care expenditures and out-of-pocket costs compared with children with other chronic illnesses.

Responses to a survey of 371 parent-child dyads revealed that $63 \%$ of the children had unmet health care needs. The highest unmet need was for behavioral therapy. Only $18.9 \%$ of these children had a medical home. Family-centered coordinated care was available only to a few of those children with a medical home. Children with ASD who had a medical home were more likely to have adequate access to needed services (Farmer et al., 2014).

These findings were supported in a larger sample of families with children with ASD. Data from the National Survey of Children with Special Health Care Needs $(N=30,055)$ were examined to determine whether having a medical home reduced unmet needs for specialty care services for children with ASD. The majority of parents reported that their children had a need for these services. Only $12.9 \%$ reported having a medical home. Children with ASD who had fewer unmet needs were more likely to have received family-centered and coordinated care through a medical home (Cheak-Zamora \& Farmer, 2015).

A systematic review was conducted to determine whether medical home models promote the transition to primary adult health care for adolescents with ASD. Of the nine articles reviewed, none discussed the use of medical homes in the transition of adolescents with ASD into adult primary care practices. The authors recommend that nurses work within an interdisciplinary framework to educate adult health care providers regarding the needs of this population and recommend the evaluation of the medical home transition model for this vulnerable population (Rogers \& Zeni, 2015).

\section{Outcomes Related to CYSHCN in Foster Care}

On any given day, there are approximately 415,000 children in foster care in the United States. In 2014, more than 650,000 children spent time in U.S. foster care (U.S. Department of Health and Human Services [DHHS], 2017). Children in foster care are a vulnerable population. Rates of psychiatric diagnoses and developmental disorders are as high as $50 \%$, with about $80 \%$ of this population needing mental health treatment (Hutchinson, 2013).

In 2008, the Fostering Connections to Success and Increasing Adoptions Act was passed. This act requires all states to develop a plan for the continuous oversight and coordination of health care services for all children in foster care, including the possible use of a medical home model (Child Welfare League of America, 2008). In the state of Illinois, a program called HealthWorks, based on a medical home model, was tested to see if it could ensure that children in foster care could obtain quality health care. Foster care children in this program demonstrated better health outcomes and higher immunization rates. In addition, there were higher rates of primary care and well-child visits and lower utilization of emergency room care for children with chronic illnesses (Jaudes, Champagne, Harden, Masterson, \& Bilaver, 2012).

\section{Transition of CYSHCN Into Adult Care}

Some medical homes include coordination of services for the transition from pediatric to adult providers to ensure that CYSHCN have continuous care. According to the AAP, the goal of transition in health care for young adults with special needs is to maximize lifelong 
functioning and potential through the provision of high-quality, developmentally appropriate health care services that continue uninterrupted as the individual moves form adolescence to adulthood (AAP, 2002). Transition strategies should be incorporated into the medical home and should be discussed early in an adolescent's care (Lemly, Weitzman, \& O'Hare, 2013).

One model of the medical home for the transition of care is the U Special Kids program at the University of Minnesota. This model was described as a medical home designed to help youth achieve optimal health and functioning. A PNP served as a case manager. Components of the transition plan include a concisely written health history summary to promote shared understanding of the adolescent's and family's strengths and skills and effective communication between the health care providers and the family (Kelly, Kratz, Bielski, \& Rinehart, 2002). A leading expert in the field of CYSHCN transitions, Betz (Betz, 1998; Betz, Lobo, Nerhinng, \& Bull, 2013; Betz, Smith, \& Macia, 2010) describes assessment and intervention strategies that can be used by pediatric nurses and advanced practice nurses to facilitate CYSHCN's successful transitions to adult health.

\section{IMPLICATIONS OF THE GUIDELINE FOR THE FOLLOWING AREAS OF NURSING PRACTICE}

\section{Clinical}

Health care providers have the opportunity to make contact with children, youth, and their families on a daily basis. During these points of contact, providers should discuss the families' health insurance and the benefits of access to care through a health care home. This is particularly true for families who go to the emergency department on a more regular basis. In the majority of health care models reviewed, a nurse or PNP played a vital role, often as a case coordinator. The nurse/case manager developed individualized health plans for children and their families, providing seamless inpatient and outpatient care.

The use of a health care home can result in holistic care that improves health outcomes and patient satisfaction while decreasing health care costs. Holistic care takes into account the overall needs of the family and child/adolescent patient. Instead of episodic visits to treat an illness or injury, a child/youth with a health care home will have a base for all health care needs. Characteristics of health care home include accessibility, continuity, comprehensiveness, compassion, cultural effectiveness, and family centeredness. For additional resources pertaining to the health care home, refer to the supplemental files listed in Box 1.1.

As depicted in the case study in this chapter, José is a 10-year-old Hispanic boy with asthma. Since José's family does not have health insurance, he is treated for his acute asthma symptoms at walk-in clinics or emergency departments. If José had a health care home, his asthma could be treated in a more preventive manner with a comprehensive plan of care developed by an interprofessional group of health care providers. José's family would be included in the plan of care. In addition, participation in health care homes can increase the quality of communication between providers and families, as well as a decrease the cost of health care delivered primarily through an emergency department.

\section{Education}

Health care providers should be introduced to the concept and benefits of a health care home for children, youth, and their families during their educational programs. In the literature reviewed for this chapter, education of both health care providers and youth and their families 


\section{Box 1.1 Listing of Supplemental Files Pertaining to Clinical Practice}

\begin{tabular}{|c|l|}
\hline Supplemental File 1.1 & $\begin{array}{l}\text { Patient-Centered Medical Home Decision Maker Brief: Ensuring } \\
\text { That Patient-Centered Medical Homes Effectively Serve Patients With } \\
\text { Complex Health Needs (Lipson, Rich, Libersky, \& Parchman, 2011) }\end{array}$ \\
\hline Supplemental File 1.2 & $\begin{array}{l}\text { Patient-Centered Medical Home Decision Maker Brief: The Patient- } \\
\text { Centered Medical Home: Strategies to Put Patients at the Center of Pri- } \\
\text { mary Care (Peikes, Genevro, Scholle, \& Torada, 2011) }\end{array}$ \\
\hline Supplemental File 1.3 & $\begin{array}{l}\text { Coordinating Care for Adults With Complex Care Needs in the Patient- } \\
\text { Centered Medical Home: Challenges and Solutions (Rich, Lipson, } \\
\text { Libersky, \& Parchman, 2012) }\end{array}$ \\
\hline Supplemental File 1.4 & $\begin{array}{l}\text { Building Medical Homes in State Medicaid and CHIP Programs (Kaye \& } \\
\text { Takach, 2009) }\end{array}$ \\
\hline Supplemental File 1.5 & $\begin{array}{l}\text { Engaging Patients and Families in the Medical Home (Scholle, Torda, } \\
\text { Peikes, Han, \& Genevro, 2010) }\end{array}$ \\
\hline
\end{tabular}

CHIP, Child Health Insurance Program.

played an important role in the positive outcomes of the use of a health care home. Continuing education was often provided to all health care workers in a practice where a health care home model was being implemented. This education included training on quality improvement and the principles of a health care home. A designated health care provider, often a nurse, was available to offer information and support to families in health care home models as well as coordinate care needs. Families that received care in health care home models were more likely to report improvements in their experiences of care and an increased satisfaction with care coordination.

The concept of a health care home can be incorporated into an undergraduate nursing program in a variety of ways. For example, in maternity and pediatrics courses, the idea of a health care home can be introduced when discussing well-child visits and immunizations. It can be further emphasized when describing child/youth/adolescent health and sports physicals that are usually required at the beginning of every school year. If a youth is hospitalized, discharge planning should always include a referral to a health care home. In clinical and simulation settings, faculty can give specific examples of the use of a health care home and the ways that it can positively influence pediatric health outcomes and family satisfaction.

At the graduate level, content related to a health care home can be incorporated into clinical nurse specialist (CNS), PNP, and family nurse practitioner (FNP) programs. When developing a plan of care, students should include referrals to a health care home. Policy courses can integrate content on pediatric health care homes from a macro perspective in terms of health care accessibility, coverage, and cost. Advanced practice nurses are educated to function as effective primary care providers and coordinators in pediatric health care homes.

Although professional pediatric organizations have position papers on topics such as access to care, quality care, and models of care, few have detailed recommendations for the 
incorporation of the concept of a health care home in education, practice, administration, or research. The AAP introduced the concept of a medical home in 1967. Over the years, additional position papers were developed. The focus of these position papers is that a health care home is an important way to increase access to care, reduce health disparities, and better integrate health care within the public health system (Grant \& Greene, 2012).

In 2014, the Society of Pediatric Nurses (SPN, 2014a) published the position paper, Child Health Content in the Undergraduate Curriculum. One of its recommendations was that health promotion and prevention, including risk and behavioral assessments with continuous focus on safety promotion and injury prevention, be included in the core content for pediatric nursing courses. In addition, the position paper recommended that clinical experiences should occur in an environment where students can collaborate with interdisciplinary health care providers who role-model an exemplary practice of family-centered care. SPN (2014b) also published the position paper, Family-Centered Care Content in Nursing Education Curriculums, which recommended the use of a holistic perspective of family-centered care. Specific recommendations for course content were included. Although the term bealth care bome is not used in these position papers, the concepts are similar.

Recently, the NAPNAP published a position statement on Pediatric Health Care/Medical Home: Key Issues on Care Coordination, Transitions, and Leadership (2016). The position paper upholds that all children must have access to comprehensive pediatric health care services that are delivered by the qualified pediatric health care professionals of a family's choice. The position paper concludes that "these recommendations require the education, knowledge and skills to successfully lead, coordinate, and manage care within health care that focuses on care coordination, holistic care and family well-being" (NAPNAP, 2016, p. 2). Continued efforts must be made to incorporate education on pediatric health care home at all levels of nursing education, as well as all levels of education of other health professionals.

\section{Policy}

The majority of studies reviewed on the use of a health care home/medical home document outcomes of increased quality and reduced costs (Antonelli et al., 2008; Cooley et al., 2009; Homer et al., 2008). The health care home model supports the goals of the PPACA to increase the quality, accessibility, and affordability of health insurance and health care to all. Further efforts need to be made in the area of the coordination of health care services during the transition from pediatrics to adult care. In addition, inequalities of services for CYSHCN related to racial/ethnic characteristics still exist. Improvements in these areas might be seen with more consistent use of instruments such as the MHI. These instruments can be used to help practice sites establish their individual baseline data and document improvements. Federal and state initiatives aimed at increasing the delivery of health care for children, youth, and their families through the health care home model must be supported. Professional nursing organizations can develop specific guidelines for the support and incorporation of the concept of a health care home in education, practice, and research. In addition, these organizations can create and support initiatives aimed at improving the quality of care and health outcomes for youth and their families.

The review of literature consistently documented positive outcomes when a pediatric nurse or nurse practitioner was included in the plan of care. The NAPNAP position paper recommended that provider-inclusive language should be used in all legislation and policies regarding any health care/medical home issues (NAPNAP, 2016). 


\section{RESEARCH}

This literature review suggested that health care services, delivered in a patient-centered health home, resulted in positive patient outcomes, including reductions in health care utilization, improvements in health outcomes, and patient satisfaction. However, many of the studies did not have a comparison patient group who were not enrolled in a health home. Given the multiple definitions of health home, there is a need for large-scale clinical trials with systematic measurement of the essential elements of a health home that predict improvements in patient outcomes. Future research needs to answer the question of which essential elements for a health care home result in improved outcomes for chronic versus acute conditions: Are they similar or different? In addition, most studies were not longitudinal so that health outcomes could be determined over time. Similarly, studies have not focused specifically on the impact on costs for patients enrolled in health homes.

Predictive studies and consistent evaluation metrics, such as the MHI used in many of the studies reviewed in this chapter, would contribute to the scientific rigor and interpretation of the outcome data related to patient outcomes and associated costs (i.e., return on investment). Although the outcomes are promising, research is needed to determine the essential elements of a "model" health home and the cost versus benefits to patients enrolled in it. For additional information on selected research designs and methods for evaluating health care homes, refer to the supplemental files listed in Box 1.2.

\section{CASE STUDY}

José Ramirez is a 10-year-old Hispanic child diagnosed at 6 years of age with persistent asthma. $\mathrm{He}$ is the oldest of five children living with his parents on a horse farm in Kentucky. The Ramirez family emigrated from Mexico 2 years ago. The family speaks primarily Spanish at home, but José can also read and speak English. The family does not have health insurance. During the past last year, José has had frequent exacerbations of his asthma, for which he was treated at a local walk-in clinic or the hospital emergency department. José previously was prescribed a long-acting controller medication and a short-acting bronchodilator rescue inhaler, but he has not adhered to the treatment. During a recent asthma episode when the family sought care in a local emergency department, the nurse and social worker discussed with the family the need for José to have continuity of care to manage his chronic asthma. Once emergency

Box 1.2 Selected Research Designs and Methods for Evaluating Health Care Homes

\begin{tabular}{|c|l|}
\hline Supplemental File 1.6 & $\begin{array}{l}\text { Logic Models: The Foundation to Implement, Study, and Refine } \\
\text { Patient-Centered Medical Home Models (Petersen, Taylor, \& Peikes, } \\
\text { 2013) }\end{array}$ \\
\hline Supplemental File 1.7 & $\begin{array}{l}\text { Mixed Methods: Integrating Quantitative and Qualitative Data Collec- } \\
\text { tion and Analysis While Studying Patient-Centered Medical Home } \\
\text { Models (Wisdom \& Creswell, 2013) }\end{array}$ \\
\hline Supplemental File 1.8 & $\begin{array}{l}\text { Early Evidence on the Patient-Centered Medical Home. Final Report } \\
\text { (Peikes et al., 2012) }\end{array}$ \\
\hline
\end{tabular}


treatment was implemented to manage the current asthma exacerbation, the health care team discussed the next steps for managing José's symptoms, including a referral to an interprofessional health care home. The emergency department nurse provided initial reporting to the new pediatric provider to transition the child from emergency care to a health care home for comprehensive asthma care.

- Before the initial visit in the health care home, the pediatric nurse contacted a Spanish interpreter to assist in translating the care management steps to the family.

- With the interpreter, the nurse and social worker assisted the parents in completing the application forms for health insurance, in accordance with the PPACA, and discussed follow-up care for José with a pediatric health care provider in a medical group that included an allergist and a pulmonologist on staff.

- The interdisciplinary team in the health care home met to formulate a comprehensive plan of care for José with the goal of managing asthma symptoms.

- Asthma education, based on the National Asthma Education and Prevention Program (2007) guidelines, was delivered to José and his parents, and the family was given educational pamphlets written in Spanish and English.

- The importance of daily medications for controlling asthma symptoms was reviewed.

- Plans were discussed regarding medication refills and the importance of using the controller medication on a daily basis for symptom management.

- The steps for the accurate technique for using inhaled medications were reviewed, and José was asked to demonstrate the technique with a placebo inhaler.

- José was taught to use a peak flowmeter and record the peak flow numbers daily in an asthma diary so that his personal best peak flow number could be assessed by the pediatric health care provider and an asthma action plan could be developed in the followup visit.

- Pulmonary function studies were ordered as a baseline.

- Family members were assisted in understanding their role as being vital in the management of José's asthma.

- The social worker coordinated the referrals to the community-based programs for which José was eligible.

- Regular follow-up visits in the health care home were scheduled for José.

\section{Discussion}

This case clearly illustrates the importance of children with chronic conditions having comprehensive, integrated care that includes an ongoing relationship with a health care provider or providers (interprofessional team). Prominent among the needs for José and his family were health insurance and a designated health care home to provide continuity for his asthma management. Once health insurance is acquired and the child is enrolled (with assistance) in a health care home, comprehensive asthma education should begin. This education includes control of environmental triggers, medication administration, peak flow monitoring, symptom management, and appropriate nutrition, sleep, and healthy lifestyle; review of the asthma 
education should be included at each health care encounter. Interprofessional, team-based follow-up care on a consistent basis in the health care home will be integral to José's ongoing asthma care and overall health management.

\section{SUMMARY}

It is clear from the studies reviewed that children who have a health care home have better overall health outcomes than those who do not. This seems to be particularly true for CYSHCN. This review included children and youth with long-term effects of low birth rates, autism, ADHA, asthma, diabetes, obesity, and HIV. Children in foster care continue to be a vulnerable population, and mental health services for this group need to be further addressed.

The majority of studies reviewed the outcomes of the use of a health care home/medical home and document outcomes of increased quality and reduced costs. However, the articles reviewed provided no details regarding specific cost savings. In the adult population, the Geisinger's Advanced Medical Home Model was found to improve quality and value, including a downward bending of the cost curve (Steele et al., 2010). Implications for clinical, education, policy, and research were also addressed.

\section{REFERENCES}

Adams, R. C., \& Tapia, C. (2013). Early intervention, IDEA Part C services, and the medical home: Collaboration for best practice and best outcomes. Pediatrics, 132(4), e1073-e1088. Retrieved from http://pediatrics.aappublications.org/content/132/4/e1073

American Academy of Family Physicians, American Academy of Pediatrics, American College of Physicians, \& American Osteopathic Association. (2007). Joint principles of the patient-centered medical home. Retrieved from http://www.aafp.org/dam/AAFP/documents/practice_management/pcmh/ initiatives/PCMHJoint.pdf

American Academy of Pediatrics. (1992). The medical home: Ad hoc taskforce on the definition of the medical home. Pediatrics, 90(5), 774.

American Academy of Pediatrics. (2002). Medical Home Initiatives for Children with Special Needs Project Advisory Committee. The medical home. Pediatrics, 110(1 Pt. 1), 184-186.

American Academy of Pediatrics. (2013). Positioning the family and patient at the center: A guide to family and patient partnership in the medical home. Retrieved from http://www.pcpcc.org/resource/posi tioning-family-and-patient-center

American Academy of Pediatrics. (2016). What is a medical home? Retrieved from https://medicalhome info.aap.org/overview/Pages/Whatisthemedicalhome.aspx

American Academy of Pediatrics Council on Pediatric Practice. (1967). Pediatric records and a "medical home." In Standards of child care (pp. 77-79). Evanston, IL: American Academy of Pediatrics.

Antonelli, R. C., Stille, C. L., \& Antonelli, D. M. (2008). Care coordination for children and youth with special health care needs: A descriptive, multisite study of activities, personnel costs, and outcomes. Pediatrics, 122(1), e209-e216. doi:1542/peds.2007-2254

Betz, C. (1998). Facilitating the transition of adolescents with chronic conditions from pediatric to adult health care and community settings. Issues in Comprehensive Pediatric Nursing, 21(2), 97-115.

Betz, C., Lobo, M., Nerhinng, W. M., \& Bull, K. (2013). Voices not heard: A systematic review of adolescents' and emerging adults' perspectives of health care transition. Nursing Outlook, 61(5), 311336. doi:10.1016/joutlook.201301.088

Betz, C., Smith, K., \& Macia, K. (2010). Testing the transition preparation training program: A randomized controlled trial. International Fournal of Child Health, 3(4), 595-607.

Centers for Disease Control and Prevention. (2016). National survey of children with special health care needs. Retreived from https://www.cdc.gov/nchs/slaits/cshcn.htm 
Cheak-Zamora, N. C., \& Farmer, J. E. (2015). The impact of the medical home on access to care for children with autism spectrum disorders. Fournal of Autism Development Disorders, 45(3), 636-644. doi:10.1007/s10803-104-2218-3

Child Welfare League of America. (2008). Convention on the rights of the child and juvenile justice. Retrieved from https://www.scribd.com/document/11441562/Child-Welfare-League-of-America -Vol-7-No-1-Summer-2008

Child Welfare League of America. (2015). The President's FY 2013 Budget and Children. Retrieved from http://www.cwla.org/wp-content/uploads/2014/05/THEPRESIDENTFY13BUDGET.pdf

Cooley, W. C., McAllister, J. W., Sherrieb, K., \& Clark, R. E. (2003). The Medical Home Index: Development and validation of a new practice-level measure of implementation of the medical home model. Ambulatory Pediatrics, 3(4), 173-180.

Cooley, W. C., McAllister, J. W., Sherrieb, K., \& Kauhlthau, K. (2009). Improved outcomes associated with medical home implementation in pediatric primary care. Pediatrics, 124(1), 358-364. doi:10 .1542/peds.2008-2600

Cowell, J., \& Swartwout, K. (2006). Health care home: Ensuring access to a regular health provider. In M. Craft-Rosenberg \& M. Krajicik (Eds.), Nursing excellence for children and families. New York, NY: Springer Publishing.

Damiano, P. C., Momany, E. T., Tyler, M. C., Penziner, A. J., \& Lobas, J. G. (2016). Cost of outpatient medical care for children and youth with special health care needs: Investigating the impact of the medical home. Pediatrics, 118(4), e1187-e1194. doi:10.1542/peds.2005-3018

Domino, M. E., Humble, C., Lawrence, W. W., \& Wegner, S. (2009). Enhancing the medical homes for children with asthma. Medical Care, 47(11), 1113-1120. doi:10.1097/MLR0b013e3181adcc65

Drumond, A., Looman, W. S., \& Phillips, A. (2012). Coping among parents of children with special health care needs with and without a health care home. Fournal of Pediatric Health Care, 26(4), 266-276. doi:10.1016/jpedhc.2010.12.005

Farmer, J. E., Clark, M. J., Drewel, E. H., Swenson, T. M., \& Ge, B. (2011). Consultative care coordination through the medical home for CSHCN: A randomized controlled trial. Maternal Child Health Fournal, 15(7), 1110-1118. doi:10.1007/s10995-010-0658-8

Farmer, J. E., Clark, M. J., Mayfield, W. A., Cheak-Zamora, N., Marvin, A. R., Law, J. K., \& Law, P. (2014). The relationship between the medical home and unmet needs for children with autism spectrum disorders. Maternal Child Health Fournal, 18(3), 672-680. doi:10.1007/s10995-013-1292-z

Gordon, J. B., Colby, H. H., Bartlet, T., Jablonski, D., Krauthoefer, M. L., \& Havens, P. (2007). A tertiary care-primary care partnership model for medically complex and fragile children and youth with special health care needs. Archives of Pediatric Medicine, 161(10), 937-944. doi:10.1001/archpedi .161 .10 .937

Grant, R., Bowen, S. K., Neidell, M., Prinz, T., \& Redlener, I. E. (2010). Health care savings attributable to integrating guidelines-based asthma care in the pediatric medical home. Fournal of Health Care for the Poor and Underserved, 21(Suppl. 2), 82-92. doi:10.1353/hpu.0.0308

Grant, R., \& Greene, D. (2012). The health care home model: Primary health care meeting public goals. American Fournal of Public Health, 102(6), 1096-1103. doi:10.2105/AJPH.2011.300397

Henes, S. T., Collier, D. N., Morrissey, S. L., Cummings, D. M., \& Kolasa, K. M. (2010). Medical nutrition therapy for overweight youth in their medical home: The KIDPOWER experience. Patient Education and Counseling, 81(1), 43-46. doi:10.1016/j.pec.2009.11.011

Homer, C. J., Klatka, K., Romm, D., Kuhlthau, K., Bloom, S., Newacheck, P., Van Cleave, J., \& Perrin, J. (2008). A review of the evidence for the medical home for children with special health care needs. Pediatrics, 122(4), e922-e937. doi:10.1542/peds.2007-3762

Hutchinson, L. (2013). Addressing the mental health needs of children in foster care: The medical home model. The Brown University Child and Adolescent Behavioral Letter, 29(11), 8.

Jackson, E. B. (2015). Outcomes of a quality improvement project examining early childhood cares and improving identification of at risk patients in a pediatric medial home setting. Fournal of Pediatric Nursing, 30(4), 543-549. doi:10.1016/j.pedn.2014.10.020

Jaudes, P., Champagne, V., Harden, A., Masterson, J., \& Bilaver, L. (2012). Expanded medical home model works for children in foster home. Child Welfare, 91(1), 9-33. 
Kaye, N., \& Takach, M. (2009). Building medical homes in state Medicaid and CHIP programs. Washington, DC. Retrieved from http://www.nashp.org/building-medical-homes-state-medicaid-and-chip -programs

Kelly, A. M., Kratz, B., Bielski, M., \& Rinehart, P. M. (2002). Implementing transitions for youth with complex chronic conditions using the medical home model. Pediatrics, 110(6), 1322-1327.

Kieckhefer, G. M., Greek, A. A., Joesch, J. M., Kim, H., \& Baydar, N. (2005). Presence and characteristics of medical home and health services utilization among children with asthma. Fournal of Pediatric Health Care, 19(5), 285-292. doi:10.1016/j.pedhc.2005.05.009

Kuo, D., Robbins, J. M., Lyle, R. E., Barrett, K. W., Burns, K. H., \& Casey, P. H. (2013). Parent-reported outcomes of comprehensive care for children with medical complexity. Family Systems Health, 31(2), 132-141. doi:10.1037/a0032341

Lemly, C. C., Weitzman, E. R., \& O'Hare, K. O. (2013). Advancing health care transitions in the medical home: Tools for providers, families and adolescents with special health care needs. Pediatrics, 25(4), 339-446. doi:10.1097/MOP.0b013e3283623d2f

Lipson, D., Rich, E., Libersky, J., \& Parchman, M. (2011). Ensuring that patient-centered medical homes effectively serve patients with complex bealth needs (AHRQ Publication No. 11). Rockville, MD: Agency for Healthcare Research and Quality. Retrieved from https://pcmh.ahrq.gov/page/ensuring-patient -centered-medical-homes-effectively-serve-patients-complex-health-needs

Long, W. E., Cabral, H. J., \& Garg, A. (2013). Are components of the medical home differentially associated with child health care utilization, health, and health promoting behavior outcomes? Clinical Pediatrics, 52(5), 423-432. doi:10.1177/0009922813479161

Maternal and Child Health Bureau. (2008). Who are children with special health care needs? Retrieved from http://www.childhealthdata.org/docs/nsch-docs/whoarecshcn_revised_07b-pdf.pdf

McAllister, J. W., Sherrieb, K., \& Cooley, W. C. (2009). Improvement in the family-centered medical home enhances outcomes for children and youth with special health care needs. Fournal of Ambulatory Care Management, 32(3), 188-196. doi:10.1097/01.JAX.000035699-.38500.dd

National Association of Pediatric Nurse Practitioners. (2016). Position statement on pediatric health care/medical home: Key issues on care coordination, transitions, and leadership. Fournal of Pediatric Health Care, 30(2), 17A-19A.

National Asthma Education and Prevention Program. (2007). Expert Panel Report 3: Guidelines for the diagnosis and management of asthma. Bethesda, MD: National Heart, Lung, and Blood Institute, National Institutes of Health. Retrieved from http://www.nhlbi.nih.gov/guidelines/asthma/asthg dln.htm

National Center for Medical Home Implementation. (2016). Building your medical home. Retrieved from https://medicalhomeinfo.aap.org/national-stateinitatives

Neff, J. M., Sharp, V. L., Muldoon, J., Graham, J., \& Myers, K. (2004). Profile of medical charges for children by health status group and severity level in a Washington State Health Plan. Health Services Research, 39(1), 73-89. doi:10.1111/j.14756773.204.00216.x

Newacheck, P., Strickland, B., \& Shonkoff, J. (1998). An epidemiologic profile of children with special health care needs. Pediatrics, 102(1 Pt. 1), 117-123.

Oswald, D. P., Bodurtha, J. N., Willis, J. H., \& Moore, M. (2016). Underinsurance and key health outcomes for children with special health care needs. Pediatrics, 119(2), e341-e347. doi:10.1542/peds .2006 .2218

Palfrey, J. S., Sofis, L. A., Davidson, E. J., Liu, J., Freeman, L., \& Ganz, M. (2004). The Pediatric Alliance for Coordinated Care: Evaluation of a medical home mode. Pediatrics, 113(Suppl. 5), 1507-1516.

Peikes, D., Genevro, J., Scholle, S. H., \& Torada, P. (2011). The patient-centered medical home: Strategies to put patients at the center of primary care (AHRQ Publication No. 11-0029). Rockville, MD: Agency for Healthcare Research and Quality. Retrieved from https://pcmh.ahrq.gov/sites/default/files/ attachments/strategies-to-put-patients-at-center-of-primary-care-brief.pdf

Peikes, D., Zutshi, A., Genevreo, J., Smith, K., Parchman, M., \& Meyers, D. (2012). Early evidence on the patient-centered medical home: Final report (AHRQ Publication No. 12-0020-EF). Rockville, MD: Agency for Healthcare Research and Quality. Retrieved from https://pcmh.ahrq.gov/sites/default/ files/attachments/early-evidence-on-pcmh-white-paper.pdf 
Petersen, D., Taylor, E. F., \& Peikes, D. (2013). Logic models: The foundation to implement, study, and refine patient-centered medical home models (AHRQ Publication No. 13-0029-EF). Rockville, MD: Agency for Healthcare Research and Quality.

Quattrin, T., Roemmich, J. N., Paluch, R., Yu, J., Epsstein, L. H., \& Echer, M. A. (2014). Treatment outcomes of overweight children and parents in the medical home. Pediatrics, 134(2), 209-297. doi:10 $.1542 /$ peds.2013-4084

Raphael, J. L., Cooley, W. C., Vega, A., Lowalkowski, M. A., Train, X., Treadwell, J., . . Giordano, T. P. (2015). Outcomes for children with chronic conditions associated with parent- and provider-reported measures of the medical home. Fournal of Health Care for the Poor and Underserved, 26(2), 358-376. doi:10.1353/hpu.2015.0051

Rich, E., Lipson, R. E., Libersky, J., \& Parchman, M. (2012). Coordinating care for adults with complex care needs in the patient-centered medical home: Challenges and solutions (AHRQ Publication No. 12-0010EF). Rockville, MD: Agency for Healthcare Research and Quality. Retrieved from https://pcmh .ahrq.gov/sites/default/files/attachments/coordinating-care-for-adults-with-complex-care-needs -white-paper.pdf

Richmond, N. E., Tran, T., \& Berry, S. (2012). Can the medical home eliminate racial and ethnic disparities for transition services among youth with special health care needs? Maternal Child Health Fournal, 16(4), 824-833. doi:10.1007/s10995-011-0785-x

Rogers, K., \& Zeni, M. B. (2015). Systematic review of medical home models to promote transitions to primary adult health care for adolescents living with autism spectrum disorder. Worldviews on Evidence-Based Nursing, 12(2), 98-107. doi:10.1111/WVN.12085

Salas, J., Xaverius, P. K., \& Chang, J. J. (2012). Does a medical home influence the effect of low birth weight on health outcomes? Maternal Child Health Fournal, 16(Suppl. 1), S143-S150. doi:10.1007/ s10995-012-1003-1

Scholle, S. H., Torda, P., Peikes, D., Han, E., \& Genevro, J. (2010). Engaging patients and families in the medical home (AHRQ Publication No. 10-0083-EF). Rockville, MD: Agency for Healthcare Research and Quality.

Seipel, M. M. (2011). The impact of medical home on selected children's health outcome. Social Work in Health Care, 50(5), 347-359. doi:10.1080/00981389.2011.567129

Society of Pediatric Nurses. (2014a). Position statement: Child health content in the undergraduate curriculum. Retrieved from http://www.pedsnurses.org/positionstatements

Society of Pediatric Nurses. (2014b). Position statement: Family-centered care content in nursing education curriculums. Retrieved from http://www.pedsnurses.org/positionstatements

Steele, G. D., Haynes, J. A., Davis, D. E., Tomcavage, J., Stewart, W. F., Graf, T. R., . . Shikles, J. (2010). How Geisinger's advanced medical home model argues the case for rapid-cycle innovation. Health Affairs, 29(11), 2047-2053. doi:10.1377/hlthaff.2010.0840

Strickland, B. B., Jones, J. R., Ghandour, R. M., Kodan, M. D., \& Newacheck, P. W. (2011). The medical home health care access and impact for children and youth in the United States. Pediatrics, 127(4), 604-611. doi:10.1542/peds.2009.35553

Toomey, S. L., Chan, E., Ratner, J. A., \& Schuster, M. A. (2011). The patient-centered medical home, practice patterns, and functional outcomes for children with attention deficit/hyperactivity disorder. American Pediatrics, 11(6), 500-507. doi:10.1016/j.acap.2011.08.010

Tregnago, M. K., \& Cheak-Zamora, N. C. (2012). Systematic review of disparities in health care for individuals with autism spectrum disorders in the United States. Research in Autism Spectrum Disorders, 6(3), 1023-1031. doi:10.1016/j.rasd.20120.01.005

Wisdom, J., \& Creswell, J. W. (2013). Mixed methods: Integrating quantitative and qualitative data collection and analysis while studying patient-centered medical home models (AHRQ Publication No. 13-0028EF). Rockville, MD: Agency for Healthcare Research and Quality. Retrieved from https://pcmh .ahrq.gov/sites/default/files/attachments/MixedMethods_032513comp.pdf

Wood, D., Winterbaurer, N., Sloyer, P, Jobli, E., Hou, T., McCaskill, Q., \& Livingood, W. C. (2009). A longitudinal study of a pediatric practice-based versus an agency-based model of care coordination for children and youth with special health care needs. Maternal Child Health fournal, 13(5), 667-676. doi:10.1007/s10995-008-0406-5 
Wood, M. R., \& Bolyard, D. (2011). Making education count: The nurse's role in asthma education using a medical home model of care. Fournal of Pediatric Nursing, 26(6), 552-558. doi:10.1016/j.pedn .2010 .06 .009

U.S. Department of Health and Human Services. Children's Bureau, Administration on Children, Youth and Families, Office of the Administration for Children and Families. (2017). Child Welfare Outcomes 2010-2014. Report to Congress. Retrieved from https://www.acf.hhs.gov/sites/default/ files/cb/cwo10_14.pdf

Yehia, B. R., Aqua, A. L., Schranz, A., Korthusi, P. T., Gaur, A. H., Rutstein, R., . . Gebo, K. A. (2013). Conformity of pediatric/adolescent HIV clinics to the patient-centered medical home care model. AIDS Patient Care and STDs, 27(5), 272-279. doi:10.1089/apc.2013.0007 